\title{
Congenital Absence of Unilateral Lumbar Articular Process - A Case Report -
}

\author{
Dae Moo Shim*, Sung Kyun $\mathrm{Oh}^{\dagger}$ \\ *Department of Orthopedic Surgery, Wonkwang University, School of Medicine, Ik San, Korea \\ ${ }^{\dagger}$ Department of Orthopedic Surgery, School of Medicine, Wonkwang University Sanbon Hospital,Gunpo,Korea
}

\begin{abstract}
A congenital absence of a lumbar articular process is a rare condition with an uncertain etiology. However, an intervertebral instability caused by this anomaly can cause occasional lower back pain. A 20 years old man presented with lower back pain. The physical examination revealed no neurological deficits. Plain radiographs of the lumbar spine revealed an absence of the left inferior articular process at the fourth lumbar vertebra associated with hypoplasia of the left lamina. The patient's symptoms were resolved after conservative treatment. We report a case of a congenital absence of articular process at the fourth lumbar vertebra.
\end{abstract}

Key Words: Lumbar anomaly, Inferior articular process

\section{Introduction}

A congenital absence of the unilateral lumbar inferior articular process is a rare spinal anomaly. The etiology is presumed to be due to a dysfunction of the ossification center during fetal life. We report a case of unilateral absence of the fourth inferior articular process with a review of the relevant literature, and suggest a mechanism for the back pain.

\section{Case Report}

A twenty year old male patient visited our outpatient clinic complaining of low back pain. He was a new recruit in the army, and the acute back pain had occurred approximately one month earlier after entering an army training camp for recruits. He had previously experienced back pain after hard work or hard exercise for several years. The findings of a physical examination were unremarkable, except for mild tenderness at the left lumbar paravertebral area. No pathological reflexes were noted. The straight leg raising test was negative.

The plain radiograph showed an absence of the left inferior articular process at the fourth lumbar vertebra. A hypoplastic defect of the left lamina was also noted (Fig. 1).

A CT scan confirmed the absence of the unilateral lumbar apophyseal joint due to an inferior articular process defect and a hypoplastic defect of the unilateral lamina (Fig. 2). However, the contralateral apophyseal joint was normal and did not show any pathological changes, such as arthrosis or hypertrophy. There was no evidence of disc herniation.

The patient was managed conservatively and a role change to the administrative department in the army was recommended. He returned to activity as an administrative office soldier and the severe low back pain has not returned for 2 years.

\section{Discussion}

The ossification center of inferior articular process has

Received Jul 30, 2008; 1st revised Aug 28, 2008; 2nd revised Sep 10, 2008; 3rd revised Sep 30, 2008; accepted Sep 30, 2008

Corresponding author: Sung Kyun Oh, MD

Department of Orthopedic Surgery ,School of Medicine,Wonkwang University Sanbon Hospital

Sanbondong, Gunpo, 435-040, Korea

Tel: +82-31-390-2224, Fax: +82-31-390-2244, E-mail: niceo@ hanmail.net 

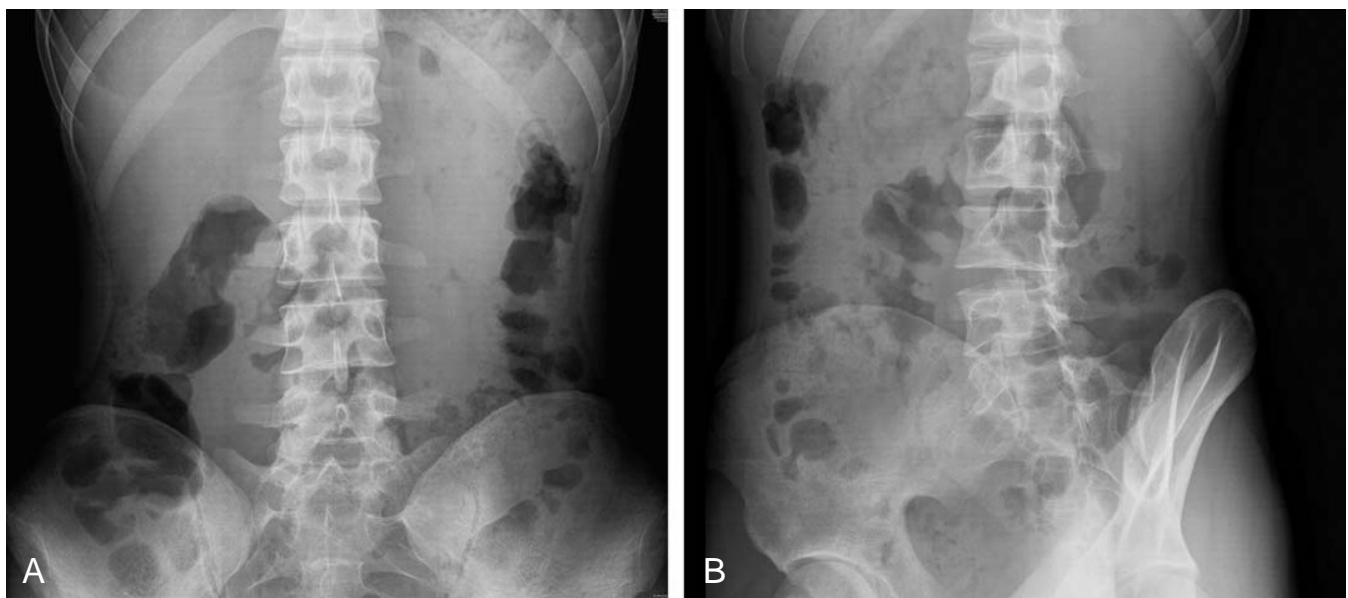

Fig. 1. Plain lumbar spine antero-posterior (A), and oblique view (B) shows a congenital absence of the left inferior articular process of L4 .
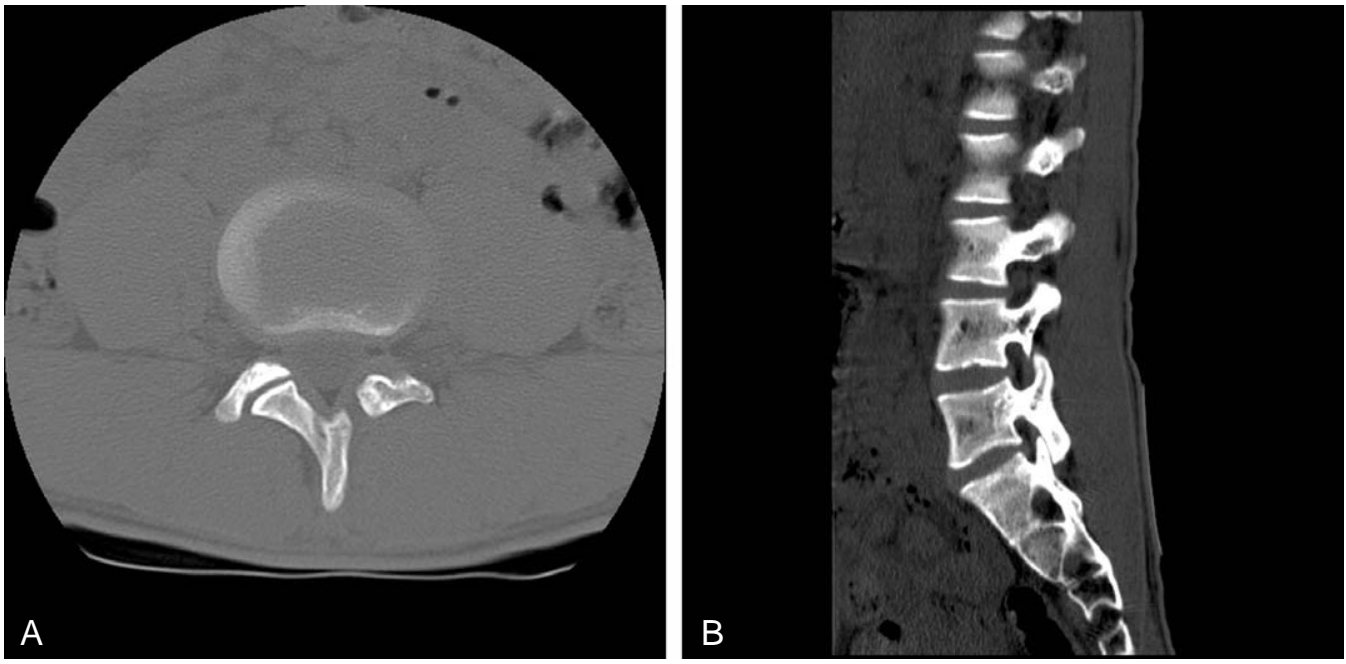

Fig. 2. CT scan shows an absence of the left unilateral lumbar facet joint and hyoplasia of the lamina.

not been demonstrated. Therefore, it is difficult to explain the basis of an ossification center failure as the cause of this anomaly. However, it is believed that this anomaly is a posterior element defect caused by fusion failure between the primary ossification centers lying at the base of the articular facet .

In a study of 1,539 examinations, only two cases of congenital anomaly of the lumbosacral facets were found ${ }^{1}$. Of 4,200 cadever dissections in another series, not a single case of lumbosacral facet defect was identified ${ }^{2}$. In 1962, Blumel could not find any evidence of unilaterally absent lumbar or sacral facets in 264 cases of congenital spinal anomalies ${ }^{3}$.

Keim and Keagy 4 , in 1967, reviewed the literature from 1900 to 1967 and found less than 12 cases. They reported three symptomatic cases of their own, which were diagnosed radiologically. Klinghoffer et al. ${ }^{5}$ reported two additional cases in 1975. In one of their asymptomatic cases, surgery was performed because the absent facet was believed to represent a destructive process. The biopsy failed to reveal any pathology. The second patient was symptomatic but a 9 year follow up failed to demonstrate any significant interval changes and the patient became asymptomatic after conservative therapy.

In 1992, Ikeda et al. ${ }^{6}$ reported three cases of a lumbosacral facet defect in three young women. They suggested that an intervertebral instability caused by these defects to be the cause of the low back pain. Takashi et al. ${ }^{7}$, in 2001, reported four symptomatic cases of congenital absence of the lumbar articular process. Among them, three patients had radiating pain, which improved after decompression with posterolateral lumbar fusion. In Korea, only three cases of a congenital unilateral articular process absence have been reported since the first report at the fourth lumbar in $1990^{8}$. Among them, one patient was 
symptomatic, and decompression with posterolateral fusion was performed for a concurrent spinal stenosis. The etiology of this anomaly is still unknown but the consensus is that is the result of a failure of ossification and impaired ossification due to insufficient blood supply in fetal life ${ }^{2,4}$. The mechanism of low back pain was suggested to be a microfracture of the hypertrophic facet joint, which was caused by a concentration of stresses. However, it is difficult to explain the pain in young patients, as in the current patient, who showed no arthritis or pathological changes to the facet joint on the CT scan. It appears that the back pain may be due to intervetebral instability in young patients ${ }^{4,6,9}$. A biomechanical study of lumbar spinal instability, particularly in the axial direction, performed after a unilateral facetectomy supports this hypothesis ${ }^{10}$. In addition, the patient's back pain generally occurred after mild trauma for years, which is believed to be the clinical instability symptom. Most symptomatic low back pain improved after conservative therapy. However, in the case of radiating pain, CT or MRI should be performed to search for other pathologies, such as disc herniation or stenosis. Decompression and fusion should be considered in patients with persistent radiating back pain.

\section{REFERENCES}

1. Rowe GG: Anomalous vertebrae from the lumbosacral column of man. Anat Rec 1950; 107: 171-179.

2. Roche MB, Rowe GG: Anomalous centers of ossification for inferior articular processes of the lumbar vertebrae. Anat Rec 1951; 109: 253-259.

3. Blumel J, Evans EB, Hadnott JL, Eggers GW: Congenital skeletal anomalies of the spine: an analysis of the charts and roentgenograms of 264 patients. Am Surg 1962; 28: 501-509.

4. Keim HA, Keagy RD: Congenital absence of lumbar articular facets. A report of three cases. J Bone Joint Surg Am 1967; 49: 523-526.

5. Klinghoffer L, Murdock MG, Hermel MB: Congenital absence of lumbar articular facets. Report of two cases. Clin Orthop Relat Res 1975; 106: 151-154.

6. Ikeda K, Nakayama Y, Ishii S: Congenital absence of lumbosacral articular process: report of three cases. J Spinal Disord 1992; 5: 232-236.

7. Takashi K, Kasama F, Sato K, Kanabuchi T, Sato T: Congenital absence of lumbar articular process;report of four cases. Orthop Surg Traumatol 2001; 44: 1321-1328. Japanese.

8. Shin BJ, Shin YS, Kim YI, Rah SK, Choi CU: Conjoined nerve roots associated with congenital lumbosacral articular facet. J Korean Spine Surg 1995; 2: 290-295.

9. Segal D, Franchi AV: Congenital absence of lumbar facets as a cause of lower-back pain. Spine 1986; 11: 7880.

10. Abumi K, Panjabi MM, Kramer KM, Duranceau J, Oxland T, Crisco JJ: Biomechanical evalucation of lumbar spinal stability after graded facetectomies. Spine 1990; 15: 1142-1147. 